\title{
Pattern of HIV-1 Drug Resistance among Adults on ART in Nigeria*
}

\author{
Georgina N. Odaibo ${ }^{1}$, Prosper Okonkwo ${ }^{2}$, Isaac F. Adewole ${ }^{3}$, David O. Olaleye ${ }^{1 \#}$ \\ ${ }^{1}$ Department of Virology, College of Medicine, University of Ibadan, Ibadan, Nigeria; ${ }^{2}$ AIDS Prevention Initiative Nigeria, Arab \\ Contractor Building, Abuja, Nigeria; ${ }^{3}$ Department of Obstetrics and Gynecology, College of Medicine, University of Ibadan, Ibadan, \\ Nigeria. \\ Email: \#davidoolaleye@gmail.com
}

Received July $1^{\text {st }}, 2013$; revised July $20^{\text {th }}, 2013$; accepted July $25^{\text {th }}, 2013$

Copyright (C) 2013 Georgina N. Odaibo et al. This is an open access article distributed under the Creative Commons Attribution License, which permits unrestricted use, distribution, and reproduction in any medium, provided the original work is properly cited.

\begin{abstract}
Background: The development of anitiretroviral drug resistance may limit the benefit of antiretroviral therapy. Therefore the need to closely monitor these mutations, especially the use of ART is increasing. This study was therefore designed to determine the ARV drug resistance pattern among ART naïve and expose individuals attending a PEPFAR supported by antiretroviral clinic in Nigeria. Methodology: The study participants included patients attending the PEPFAR supported by University College Hospital (UCH), Ibadan ART clinic who have been on HIV treatment for at least one year with consecutive viral load of over $2000 \mathrm{copies} / \mathrm{ml}$ as well some ART Naïve individuals with high ( $>50,000$ copies $/ \mathrm{ml}$ ) baseline viral level attending the hospital for pre-ART assessment. Blood sample was collected from each individual for CD4 enumeration, viral load level determination and DNA sequencing for genotypic typing. Antiretroviral drug resistance mutations (DRM) were determined by using the Viroseq software and drug mutations generated by using a combination of Viroseq and Stanford algorithm. DRM were classified as major or minor mutations based on the June 2013 Stanford DR database. Results: The most common major NRTI, NNRTI and PI mutation were D67N (33.3\%), Y181C (16.7\%) and M46L/I (55.6\%) respectively. Lamivudine (3TC) and emtricitabine (FTC); nevirapine (NVP) and nelfinavir (NFV) were the most common NRTI, NNRTI, and PI drugs to which the virus in the infected individuals developed resistance. Isolates from 4 patients were resistant to triple drug class, including at least one NRTI, NNRTI and a PI. Only one (4.8\%) of the isolates from drug Naïve individuals had major DRM that conferred resistance to any drug. Conclusion: Demonstration of high rates of antiretroviral DRM among patients on $1^{\text {st }}$ and $2^{\text {nd }}$ line ART and the presence of DRM in drug Naïve individuals in this study show the importance of surveillance for resistance to ARV in line with the magnitude of scaling up of treatment program in the country.
\end{abstract}

Keywords: Antiretroviral Therapy; Drug Resistance Mutation; ART Naïve; 1st and 2nd Line ART

\section{Introduction}

HIV/AIDS continues to be a global health problem since its discovery in 1981 [1] with over 33 million people living with the virus at the end of 2011 [2]. The first case of AIDS was reported in Nigeria in 1986 and the rate of HIV infection in the country increased steadily from $0.6 \%$ in 1987 to a peak of $5.8 \%$ in 2003 . The last HIV national sentinel survey in the country shows that the rate of infection has declined to $3.4 \%$ [3], though the pre-

\footnotetext{
"Funding: the study was carried out with funding from Center for Disease Control and Prevention through AIDS Prevention Initiative Nigeria (APIN).

"Corresponding author.
}

valence varies by locations from a relatively low rate of $2.1 \%$ in the north central and $2.9 \%$ in south western zones respectively to a high rate of $7.5 \%$ in the north central zone of the country.

According to UNAIDS, the number of new infections globally reduced to 2.5 million in 2011 from 3.2 million in 2001 [2]. Part of the reasons for this success may not be unrelated to the wide spread use of antiretroviral therapy (ART). There are evidences that ART contributes greatly to the reduction of transmission, morbidity and mortality caused by HIV infection [4-6]. This dramatic improvement that is most prominent in the North America, Western Europe and recently Brazil, has led to the advocacy for increased access to antiretroviral drugs in 
resource limited settings [1,7-10]. Many African countries have responded positively and increased access to ART, though with support from international agencies [11-15].

In Nigeria, wide use of ART started in 2002 when the Federal Government launched the pilot HIV treatment program $[9,10]$. Additional funding for antiretroviral treatment became available in the country through the US government funded by President's Emergency Plan for AIDS Relief (PEPFAR) program and the Global Funds and thus they increased access to ART greatly. To date, over 500,000 patients are on ART in Nigeria, although this number is a far cry to the almost 1.5 million HIV positive individuals who require treatment in the country [16].

The introduction of antiretroviral therapy has substantially changed the natural history of HIV and AIDS. Unlike the 80s and early 90s, people living with HIV/ AIDS [PLWAs] now live better and longer, thus they are able to contribute meaningfully to the economy of their country. However, development of drug resistance may limit the benefit of antiretroviral therapy. Various reports have documented the increase of ARV drug resistance in different countries and regions of the world [17-21]. Although the result of a recent WHO DRM survey which reported that "rate of transmitted DR continues to remain limited in low-and-middle-income countries" [22] is assuring because of the initial skepticism $[23,24]$ by the international community, there is still the need to closely monitor these mutations in each country, especially as the use of ART increases. This study was therefore designed to determine the ARV drug resistance pattern among ART naïve and expose individuals attending the PEPFAR supported by antiretroviral clinic at the University College Hospital, Ibadan, the premier tertiary hospital in Nigeria.

\section{Methodology}

\subsection{Study Site}

This study was carried out among patients attending the antiretroviral treatment clinic of the University College Hospital (UCH), Ibadan, Nigeria. The UCH is the foremost teaching hospital located in the southwestern region of Nigeria. The hospital runs 55 weekly specialty clinics with patients' referrals from many states in the southwestern region and from other parts of the country. Antiretroviral treatment started in the hospital in 2002 when the Federal Government of Nigeria introduced ARV program in the country. The treatment program was scaled up in 2004 with support from the US government President Emergency Fund for AIDS Relief (PEPFAR) program through funding provided to the Harvard School of Public Health, Boston, USA. There are over 10,000
HIV infected individuals currently receiving care and treatment in the hospital.

\subsection{Study Population}

The study participants included patients attending the PEPFAR supported UCH ART clinic who have been on HIV treatment for at least one year with consecutive viral load of over 2000 copies/ml as well some ART Naïve patients attending the hospital for pre-ART assessment. Individuals who commenced therapy before 2005 were excluded from this study because there were reported drug stock-outs during the government of Nigeria pilot treatment program that lasted until late 2004 and some of the patients on that program were reported to have developed drug resistance mutations [20].

\subsection{HIV Viral Load Determination (RNA Quantification)}

Viral load measurement was carried using the Roche Amplicor version 1.5 with lower and upper detection limits of 400 copies/ml and 750,000 copies/ml respectively.

\subsection{HIV Drug Resistance Genotyping}

HIV RNA was extracted from 500 ul of plasma using the QIAamp Viral RNA Extraction Mini Spin Kit (Qiagen, Germany). HIV RNA was reverse transcribed to cDNA, amplified and subsequently sequenced using the Viroseq HIV-1 genotyping assay, version 2.0 as previously described by Chaplin et al. [25]. Sequences were generated using a 3130 XL genetic analyzer (Applied Biosystems) and the generated sequences were edited and compared with an HXB2 subtype B reference using the Viroseq software and list of mutations generated. The mutations were classified as minor or major base on the June 22, 2013 updated HIV drug resistance data base (http:/hivdb. standard.edu). Resistance to each drug was determined using a combination of the Viroseq and Stanford drug resistance algorithms and resistance to each drug assigned as susceptible, intermediate or resistant.

\section{Results}

A total of 46 samples were analyzed in this study. The characteristics of the patients whose samples were analyzed are shown in Table 1. The mean age of the participants was 43 years (range, $29-70$ ) and $58.7 \%$ of them were female. However more male patients seem to be failing $2^{\text {nd }}$ line treatment while more female failed $1^{\text {st }}$ line drugs. The average time on ART was 3.2 (range, 0.5 - 5.5) years and 2.8 (range, 1 - 4) years for those failing the $1^{\text {st }}$ line and the $2^{\text {nd }}$ line drugs respectively. There was a gender bias in the time between ART commencement and virologic failure for patients on $1^{\text {st }}$ line regimen. The 
average time was 4 years and 1.5 years for female and male patients respectively. Only one of the 21 patients on ART had a major resistance mutation while $71.4 \%$ of them had no resistance mutation (Table 2). Fifty percent of the patients failing $1^{\text {st }}$ line and $100 \%$ of those failing $2^{\text {nd }}$ line had major resistance mutations. About $30 \%$ of those failing $1^{\text {st }}$ line drugs did not have any resistance mutation while $19.8 \%$ of them had only minor mutations.

Table 3 shows the characteristics of individuals with major resistance mutations. The mean CD4 and median viral load of those with major resistance mutations were lower than those of the study population (Table 1). The only ART Naïve individual with a major mutation was a female with CD4 of 23 cells/ul and viral load of 78,792 copies/ml.

The most common major NRTI mutation was D67N followed by $\mathrm{T} 215 \mathrm{Y}$ and M41L while the most frequent major NNRTI mutations were Y181C and K103N. Among the PI mutations, the most frequent was M46L/I followed by V82F/S/I and then I47V (Table 4). Other mutations detected include: M184V/I (13) M41L (6), E44D (1) T69N (2), L10I/V (16), V11I (3), A98G (7), P225H (1) AND P236L (L). Table 5 shows the drugs by class to which virus developed resistance. Lamivudine (3TC) and emtricitabine (FTC); nevirapin (NVP) and nelfinavir (NFV) were the most common NRTI, NNRTI, and PI drugs respectively to which the virus in the infected individuals developed resistance. Virus from 4 of the patients were resistant to more than six antiretroviral drugs (Table 5) including 3TC, FTC, AZT, d4T, ABC, APV, FOS, IDV, LPV, NFV, TPV. Isolates from the 4 patient samples were resistant to triple drug class, including at least one NRTI, NNRTI and a PI. Interestingly the virus from one of the patients who failed $2^{\text {nd }}$ line treatment was resistant to all the eleven drugs listed above (Table 6). Virus from the only ART Naïve individual with major drug resistance mutation was resistant to the PI nelvinavir $(\mathrm{NFV})$.

Table 1. Showing characteristics of study the participants in the study.

\begin{tabular}{ccccccccccc}
\hline ART status & N & Mean age (yrs.) & Average time on ART (yrs.) & \multicolumn{2}{c}{ Gender } & \multicolumn{2}{c}{ CD4 (cells/ul) } & \multicolumn{2}{c}{ Viral load (copies/ml) } \\
\hline & & & & Male & Female & Mean & Range & Median & Range \\
Naïve & 21 & 43.6 & NA & 9 & 12 & 219 & $14-723$ & 102,755 & $8655-2,623,338$ \\
$1^{\text {st }}$ line failure & 16 & 40.7 & 2.9 & 4 & 12 & 367 & $35-1165$ & 168,008 & $3785-1,201,535$ \\
$2^{\text {nd }}$ line failure & 9 & 45.8 & 2.1 & 6 & 3 & 199 & $32-769$ & 95,261 & $3899-43,926$ \\
Total (overall) & 46 & 43.0 & NA & 19 & 27 & 267 & $14-1165$ & 100,417 & $3785-2,623,338$ \\
\hline
\end{tabular}

NA: Not Applicable.

Table 2. Resistance mutation types among patients enrolled in the study.

\begin{tabular}{cccccccc}
\hline ART status & No tested & \multicolumn{2}{c}{ No.(\%) mutations } & \multicolumn{2}{c}{ Minor mutations } & \multicolumn{2}{c}{ Major mutations } \\
\hline & & No. & $\%$ & No. & $\%$ & No. & $\%$ \\
Naïve & 21 & 15 & 71.4 & 5 & 23.8 & 1 & 4.8 \\
$1^{\text {st }}$ line failure & 16 & 5 & 31.2 & 3 & 19.8 & 8 & 50.0 \\
$2^{\text {nd }}$ line failure & 9 & 0 & 0.0 & 0 & 0.0 & 9 & 100 \\
Total (overall) & 46 & 20 & 43.5 & 8 & 17.4 & 18 & 39.1 \\
\hline
\end{tabular}

Table 3. Showing some demographic and laboratory parameters of various categories of patients with major drug resistance mutations in the study.

\begin{tabular}{ccccccc}
\hline ART status & No with MRM & \multicolumn{2}{c}{ Gender } & \multicolumn{2}{c}{ CD4 (cells/ul) } & Viral load (copies/ml) \\
\hline & & Male & Female & Mean & Range & Median \\
Naïve & 1 & 0 & 1 & 23 & NA & 78,792 \\
$1^{\text {st }}$ line failure & 8 & 3 & 5 & 199 & $35-538$ & 79,132 \\
$2^{\text {nd }}$ line failure & 9 & 6 & 3 & 199 & $32-769$ & 95,261 \\
Total (overall) & 18 & 9 & 9 & 197 & $23-769$ & 79,132 \\
\hline
\end{tabular}

MRM = Major Resistance Mutation; NA = Not Applicable. 
Table 4. Showing frequency of major resistance mutations among the study participants.

\begin{tabular}{|c|c|c|c|c|c|c|}
\hline \multirow[t]{2}{*}{ Class of drugs } & \multicolumn{2}{|c|}{ NRTI } & \multicolumn{2}{|c|}{ NNRTI } & \multicolumn{2}{|c|}{ PI } \\
\hline & Mutation & Frequency & Mutation & Frequency & Mutation & Frequency \\
\hline & M41L & 5 (27.8\%) & V179E & $1(5.6 \%)$ & L24I & $1(5.6 \%)$ \\
\hline & D67N & $6(33.3 \%)$ & G190A & $1(5.6 \%)$ & M46L/I & $10(55.6 \%)$ \\
\hline & K70R & $1(5.6 \%)$ & K101E & $1(5.6 \%)$ & $\mathrm{I} 47 \mathrm{~V}$ & $3(16.7 \%)$ \\
\hline \multirow[t]{5}{*}{ Mutations } & L210W & $3(16.7 \%)$ & K103N & $2(11.1)$ & G48V & $1(5.6 \%)$ \\
\hline & $\mathrm{T} 215 \mathrm{Y}$ & $4(22.2 \%)$ & Y181C & $3(16.7 \%)$ & $\mathrm{I} 54 \mathrm{~V}$ & $1(5.6 \%)$ \\
\hline & - & - & Y188L & $1(5.6 \%)$ & L76V & 2 (11.1\%) \\
\hline & - & - & F227L & $1(5.6 \%)$ & V82F/S/I & $4(22.2 \%)$ \\
\hline & - & - & - & - & $\mathrm{I} 84 \mathrm{~V}$ & $1(5.6 \%)$ \\
\hline
\end{tabular}

Table 5. Showing patterns of drug resistance among the study participants.

\begin{tabular}{|c|c|c|}
\hline Class of drug & Drug & $\begin{array}{l}\text { No of sample(s) with } \\
\text { resistance to each drug }\end{array}$ \\
\hline \multirow{6}{*}{ NRTIs } & 3TC & $10(55.6 \%)$ \\
\hline & FTC & 10 (55.6\%) \\
\hline & AZT & $3(16.7 \%)$ \\
\hline & STAVUDINE & $3(16.7 \%)$ \\
\hline & $\mathrm{ABC}$ & $3(16.7 \%)$ \\
\hline & TDF & $4(22.2 \%)$ \\
\hline \multirow{4}{*}{ NNRTIs } & DLV & $6(33.3 \%)$ \\
\hline & EFV & $6(33.3 \%)$ \\
\hline & NVP & 7 (38.9\%) \\
\hline & ETR & $1(5.6 \%)$ \\
\hline \multirow{7}{*}{ PIs } & APV & $3(16.7 \%)$ \\
\hline & FOS & $3(16.7 \%)$ \\
\hline & IDV & $4(22.2 \%)$ \\
\hline & SQV & $1(5.6 \%)$ \\
\hline & LPV & 2 (11.1\%) \\
\hline & NFV & 7 (38.9\%) \\
\hline & TPV & $1(5.6 \%)$ \\
\hline
\end{tabular}

\section{Discussion}

This study describes the prevalence and pattern of mutations associated with ARV drug among patients on $1^{\text {st }}$ and $2^{\text {nd }}$ line therapy as well as ART naïve patients in $\mathrm{Ni}$ geria. Our results show that more female failed $1^{\text {st }}$ line drugs and a higher average time on ART before failure among female than male patients who failed $1^{\text {st }}$ line. This finding is in accord with an earlier finding by Chaplin et
Table 6. Showing number of patients whose virus had the various drug resistance combination indicated.

\begin{tabular}{cc}
\hline Sample of number(s) & Drug resistance \\
\hline 1 & NFV \\
2 & DLV, NVP \\
1 & SQV, NFV \\
2 & 3TC, FTC, EFV \\
2 & 3TC, FTC, ETR \\
1 & DLV, EFV, NVP, TDF \\
1 & 3TC, FTC, EFV, NVP \\
1 & 3TC, FTC, DLV, NPV, NFV, IDV \\
1 & 3TC, FTC, DLV, EFV, NVP, TDF \\
1 & 3TC, FTC, DLV, EFV, NVP, NFV, TDF \\
2 & 3TC, FTC, DLV, EFV, NVP, NFV, TDF \\
1 & 3TC, FTC, AZT, d4T, ABC, \\
& APV, FOS, IDV, NFV \\
1 & 3TC, FTC, AZT, d4T, ABC, \\
& APV, FOS, IDV, LPV, ATV \\
& 3TC, FTC, AZT, d4T, ABC, \\
& APV, FOS, IDV, LPV, NFV, TPV \\
\end{tabular}

al. [26] who observed a potential difference in time to failure based on gender. These earlier workers recommended better drug adherence in women in the first 12 months and gender response to therapy as possible reason for rapid resistance mutations in men. It is therefore reasonable to suggest that problem of poor adherence may also explain why more men seem to be failing $2^{\text {nd }}$ line therapy as observed in this study. The low mean CD4+ cells and high viral load found ART among the naïve individuals is similar to previous reports from Nigeria $[25,26]$ and some other low-and-middle-income 
countries [21,27-29]. This may be due to the poor health seeking behavior in Africa where most patients seek medical attention only when their health condition has deteriorated significantly.

Only one [4.8\%] of the ART naïve individuals had any major drug resistance mutations with possible resistance to nelvinavir. Although this rate is lower than reports from Europe and some other African counties [28,30-34], it is still a cause for concern because the major source of DR in ART naïve is through transmission of resistance strains. This finding underscores the need for drug resistance surveillance among newly infected individual in order to detect DR transmitted viruses for early intervention. The $4.8 \%$ rate of major drug resistance mutations among drug naïve individuals obtained in this study is similar to the rates reported in other low and middleincome countries. A survey conducted by WHO in 20 countries showed an overall transmitted drug resistance virus rate of 3.7\% [30]. Globally, the rates of transmission of DR viruses is increasing $[20,22,32,35]$ and therefore the need for pre-ART resistance testing cannot be over emphasized. However, the cost of this testing is enormous and may be difficult to implement in resource limited settings [7].

Although antiretroviral therapy is effective in suppressing HIV-1 replication and prolonging live of infected individuals, some patients are experiencing detectable viral replication even under highly active antiretroviral therapy [36-38]. Several factors such as resistance to current drugs, poor adherence, co-infection with tuberculosis have been associated with this phenomenon [22,39-41]. In this study, 31.2\% [5/21] and 19.8\% [3/21] of the $1^{\text {st }}$ ART failures had no DR mutation and minor mutations/polymorphisms respectively. The therapeutic failure of these individuals may be due to other factors than DR mutation. The medical records of the patients showed that $50 \%$ of these individuals had drug adherence problem, 25\% had co-infection with TB and no obvious reason could be attributed to the failure in the remaining 25\%. A similar finding was reported by Abar et al. among patients failing $1^{\text {st }}$ line therapy in Djibouti [32].

The finding that $50 \%$ and $100 \%$ of those on $1^{\text {st }}$ line and $2^{\text {nd }}$ line drugs respectively had major drug resistance mutations compared to $4.8 \%$ of ART naïve indicates that these mutations developed as a result of ART use rather than transmission of resistant strains. Drug pressure as well as poor drug adherence and drug absorption rate that lead to circulation of sub-optimal blood level of drug are known factors that contribute to the development of drug resistance mutations $[22,40,42,43]$.

The M184V/I mutation was the most common minor mutation found in $72.2 \%$ of the samples which is similar to findings of other studies $[27,30,44]$ and known globally as the most common NRTI-resistance mutation [22,
45]. Although the mutations are known to cause highlevel in-vitro resistance to 3TC/FTC, they are not contraindication to 3TC/FTC due to reduction of viral replication fitness and increase susceptibility to TDF, AZT, and d4T [45]. The most common NRTI, NNRTI and PI associated major resistance mutation detected were D67N [33.3\%], Y181C [16.7\%] and M46L/I respectively. All the NRTI mutations identified [M41C, D67N, L201W, T215Y, K70R] were TAMS that are known to increase resistance to AZT, tenofovir, d4T, abacavir, and DDI [33,45]. No NRTI conferring multidrug resistance [MDR] was detected. The NNRTI mutation at position 181, Y181C is known to result in high-level ETR and RPV resistance [46-48] while the PI mutation, M46LI is known to have high-level reduced susceptibility or increase resistance to FPV/r and IDV/r [45,49].

The drugs to which each of the virus isolates was resistant to were determined using a combination of the Viroseq and Stanford algorithm. Over $50 \%$ of the patients had viruses that were resistant to 3TC or FTC. Only $16.7 \%$ of them had viruses that are resistant to AZT while no resistance to $\mathrm{d} 4 \mathrm{~T}$ was detected. These two drugs are NNRTI backbones for some of the $1^{\text {st }}$ line drugs used in the Nigeria and the results therefore indicate that Nigerian patients are responding well to these drugs and hence can continue to serve as good backbone for $1^{\text {st }}$ line antiretroviral therapy in the country. The high rate of multidrug class resistance found in this study, especially among individuals on $2^{\text {nd }}$ line therapy is of great concern and suggests the need for careful selection of second line drugs based on drug resistance testing. Genotypic testing has been shown to be beneficial in guiding appropriate ART selection [30], hence the significance of this study.

\section{Conclusions}

We have shown that the high rate of some resistance minor and major mutations occurs in HIV-1 among patients failing first and second line antiretroviral drugs in Nigeria. The study also showed occurrence of resistance mutations in HIV-1 in ARV Naïve patients in our study population. The work therefore emphasizes the importance of surveillance for resistance to ARV in line with the magnitude of scaling up of treatment program in the country.

\section{WHAT IS ALREADY KNOWN ON THIS SUB-} JECT

Previous studies have shown that development of drug resistance is a major problem associated with wide spread use of antiretroviral drugs for treatment of HIV infected patients. However there is dearth of information on the drug resistance pattern in settings with predominance of non-subtype B of HIV-1 like Nigeria.

WHAT THIS STUDY ADDS TO LITERATURE

The results of this study show the rate and pattern of 
antiretroviral drug resistance among HIV-1 infected patients failing first and second line regimens in Nigeria where non-B subtypes of the virus circulate. The high rate of multidrug resistance reported in this study, especially among patients on second line regimen is significant and will be helpful in the choice of drugs for treatment.

\section{Acknowledgement}

The ART program at the University College Hospital is supported by USG PEPFAR program through a Cooperative Agreement (No: 1U2GPS001058) from the Centers for Disease Control and Prevention to the AIDS Prevention Initiative Nigeria. The content of the manuscript are solely the responsibility of the authors and do not necessarily represent the official views of the Centers for Disease Control and Prevention. We are grateful to all the staff of the ART clinic and Virology laboratory for patient enrolment and laboratory analysis. We also appreciate our patients who participated in the study.

\section{Authors' Contribution}

GNO and DOO conceived the idea of the study, GNO, PO, IFA and DOO were involved in collection and analysis of data, PO and IFA supervised recruitment and enrolment the patients, GNO and DOO supervised the laboratory investigations. GNO wrote the draft manuscript while all authors reviewed the manuscript and approved the final version. DOO is the guarantor of the paper.

\section{Ethical Considerations}

Approval for the study was obtained from the University of Ibadan/University College hospital ethical review board. Informed consent was obtained from all participants in the study.

\section{Competing Interest}

We declare that we have no conflicting interest in the conduct of the study.

\section{REFERENCES}

[1] S. Robert, S. M. Gottlieb, M. H. Schanker, D. Joel, D. O. Weisman, F. P. Thim, A. R. Wolf and S. Andrew, "Pnuemocystiscarinii Pnuemoniaand Mucosal Candidiasis in Previously Healthy Homosexual Men-Evidence of a new Acquire Cellular Immunodeficiency,” New England Journal of Medicine, Vol. 305, 1981, pp. 1425-1431. http://dx.doi.org/10.1056/NEJM198112103052401

[2] UNAIDS, "State of the Epidemic," Report of the Global AIDS Epidemic, 2012, pp. 1-103.

http://www.unaids.org/en/media/unaids/contentassets/doc uments/epidemiology/2012/gr2012/20121120_UNAIDS_
Global_Report_2012_with_annexes_en.pdf

[3] FMOH, "National HIV Sero-Prevalence Sentinel Survey among Pregnant Women Attending Antenatal Clinics in Nigeriam,” Technical Report, 2010, pp. 1-96.

[4] S. M. Hammer, J. J. Eron Jr., P. Reiss, et al., “Antiretroviral Treatment of Adult HIV Infection: 2008 Recommendations of the International AIDS Society-USA Panel," JAMA, Vol. 300, No. 5, 2008, pp. 555-570. http://dx.doi.org/10.1001/jama.300.5.555

[5] World Health Organization, UNAIDS and UNICEF, “Towards Universal Assess: Scaling up Priority HIV/AIDS Interventions in the Health Sector,” 2010.

[6] G. Panos, G. Samonis, V. G. Alexiou, G. A. Kavarnou, G. Charatsis and M. E. Falagas, "Mortality and Mobidity of HIV-Infected Patients Receiving HAART: A Cohort Study," Current HIV Research, Vol. 6, No. 3, 2008, pp. 257-260. http://dx.doi.org/10.2174/157016208784324976

[7] P. Severe, P. Leger, M. Charles, et al., "Antiretroviral Therapy in a Thousand Patients with AIDS in Haiti," New England Journal of Medicine, Vol. 353, No. 32, 2005, pp. 2325-2334. http://dx.doi.org/10.1056/NEJMoa051908

[8] P. E. Sax, R. Islam, R. P. Walensky, et al., "Should Resistance Testing Be Performed for Treatment-Naïve HIVInfected Patients? A Cost-Effectiveness Analysis,” Clinical Infectious Diseases, Vol. 41, No. 9, 2005, pp. 13161323. http://dx.doi.org/10.1086/496984

[9] A. Mocroft, S. Vella, T. Benifield, et al., "Charging Patterns of Mortality Across Europe in Patients Infected with HIV-1," Lancet, Vol. 352, No. 9142, 1998, pp. 17251730. http://dx.doi.org/10.1016/S0140-6736(98)03201-2

[10] J. Marins, L. Jamal, S. Chen, et al., "Dramatic Improvement in Survival among Adult Brazilian AIDS Patients," AIDS, Vol. 17, No. 11, 2003, pp. 1675-1682. http://dx.doi.org/10.1097/00002030-200307250-00012

[11] J. Peterson and O. Obileye, "Access to Drugs for HIV/ AIDS and Related Opportunistic Infections in Nigeria," POLICY Project, Nigeria, 2002.

[12] O. Odutolu, B. A. Ahonsi, M. Gboun and O. M. Jolayemi, “The National Response to HIV/AIDS,” In: O. Adeyi, P. H. Kanki, O. Odutolu and J. A. Idoko, Eds., AIDS in Nigeria: "A Nation on a Threshold", Harvard University Press, Cambridge, 2006, pp. 241-279.

[13] C. Wallis, M. Papthanasopoulos, M. Fox, et al., "Lows Rate of Nucleoside Reverse Transcriptase Inhibitor (NRTI) Resistant Detected in a Well Monitored Cohort in South Africa Accessing Antiretroviral Therapy,” Antiviral Therapy, Vol. 17, No. 2, 2012, pp. 313-320. http://dx.doi.org/10.3851/IMP1985

[14] V. C. Marconi, H. Sunpath, Z. G. Lu, M. Gordon, K. Koranteng-Apeagyei, J. Hampton, S. Carpentar, et al., "Prevalence of HIV-1 Drug Resistance After Failure of a First Highly Active Antiretroviral Therapy Regimen in KwaZulu Natal, South Africa," Clinical Infectious Diseases, Vol. 46, No. 10, 2008, pp. 1589-1597. http://dx.doi.org/10.1086/587109

[15] H. Hatano, P. Hunt, J. Weidler, et al., "Rate of Vira Evolution and Risk of Losing Future Drug Options in Heavily Pretreated, HIV-Infected Patients Who Continue to Re- 
ceive a Stable, Partially Suppressive Treatment Regimen,” Clinical Infectious Diseases, Vol. 43, No. 10, 2006, pp. 1329-1336. http://dx.doi.org/10.1086/508655

[16] Nigeria's HIV/AIDS Information Website, “Current HIV/ AIDS Statistics in Nigeria.” www.nigeriahivinfo.com

[17] R. E. Nettles, T. L. Kieffer, R. P. Simmons, et al, "Genotypic Resistant in HIV-1-infcted Patients with Persistently Detectable Low Level Viremia While Receiving Highly Active Antiretroviral Therapy,” Clinical Infectious Diseases, Vol. 39, No. 7, 2004, pp. 1030-1037. http://dx.doi.org/10.1086/423388

[18] S. Palmer, M. Kearney, F. Maldarelli, et al., "Multiple, Linked Human Immunodeficiency Virus Type Drug Resistance Mutations in Treatment-Experienced Patients Are Missed by Standard Genotype Analysis,” Journal of Clinical Microbiology, Vol. 43, No. 1, 2005, pp. 406-413. http://dx.doi.org/10.1128/JCM.43.1.406-413.2005

[19] F. Doualla-Bell, T. Gaolathe, A. Avalos, et al., "Five Years Follow Up of Genotypic Resistance Patterns in HIV-1 Subtype C Infected Patients in Botswana after Failure of Thymidine Analogue-Based Regimens," Journal of the International AIDS Society, Vol. 12, 2009, p. 25. http://dx.doi.org/10.1186/1758-2652-12-25

[20] E. O. Idigbe, T. A. Adewole, G. Eisie, et al., "Management of HIV-1 Infection with a Combination of Nevirapine, Stavudine, and Lamivudine: A Preliminary Report on Nigerian Antiretroviral Program," Journal of Acquired Immune Deficiency Syndromes, Vol. 40, No. 1, 2005, pp. 65-69.

http://dx.doi.org/10.1097/01.qai.0000159516.39982.1b

[21] J. E. Gallant, A. E. Rodriguez, W. G. Weinberg, et al., "Early Virologic Nonresponse to Tenofovir, Abacavir, and Lamivudine in HIV-Infected Antiretroviral-Naïve Subjects," Journal of Infectious Diseases, Vol. 192, No. 11, 2005, pp. 921-930. http://dx.doi.org/10.1086/498069

[22] World Health Organization, "HIV Drug Resistance Report,” 2012, pp. 3-78.

[23] D. R. Kuritzkes, "Extending Antiretroviral Therapy to Resource-Poor Settings: Implications for Drug Resistance," AIDS, Vol. 18, Suppl. 3, 2004, pp. S45-S48. http://dx.doi.org/10.1097/00002030-200406003-00009

[24] J. M. Lang, J. Perriens, D. Kuritzkes and D. Zewdie, "What Policymakers Should Know about Drug Resistance and Adherence in the Context of Scaling-Up Treatment of HIV Infection,” AIDS, Vol. 18, Suppl. 13, 2004, pp. 569-574.

[25] B. Chaplin, G. Eisen, J. Idoko, D. Onwujekwe, E. Idigbe, I. Adewole, W. Gashau, S. Meloni, A. D. Sarr, J. L. Sankalé, E. Ekong, R. L. Murphy and P. Kanki, "Impact of HIV Type 1 Subtype on Drug Resistance Mutations in Nigerian Patients Failing First-Line Therapy,” AIDS Research and Human Retroviruses, Vol. 27, No. 1, 2011, pp. 71-80. http://dx.doi.org/10.1089/aid.2010.0050

[26] G. N. Odaibo, S. O. Ola, M. Landerz, U. Dietrich and D. O. Olaleye, "HIV-1 Drug Resistant Mutations in Chronically Infected Treatment Naive Individuals in the PreARV Era in Nigeria,” African Journal of Medicine \& Medical Sciences, Vol. 41, 2012, pp. 61-63.

[27] A. M. J. Wensing, D. A. van de Vijver, G. Angarano, et al., "Prevalence of Drug-Resistance HIV-1 Variants in Untreated Individuals in Europe: Implications for Clinical Management,” Journal of Infectious Diseases, Vol. 192, No. 6, 2005, pp. 958-966.

http://dx.doi.org/10.1086/432916

[28] D. Paraskevis, E. Magiokinis, A. Katsoulidou, et al., "Prevalence of Resistance-Associated Mutations in Newly Diagnosed HIV-1 Patients in Greece,” Virus Research, Vol. 112, No. 1, 2005, pp. 115-122.

http://dx.doi.org/10.1016/j.virusres.2005.03.004

[29] S. J. Litle, S. Holte, J. P. Routy, et al., “Antiretroviral-Drug Resistance among Patients Recently Infected with HIV,” New England Journal of Medicine, Vol. 347, 2002, pp. 385-394. http://dx.doi.org/10.1056/NEJMoa013552

[30] R. L. Hamers, K. C. Sigaloff, A. M. Wensing, L. C. Wallis, C. KItyo, M. Siwale, K. Mandaliya, et al., "Patterns of HIV-1 Drug Resistance after First-Line Antiretroviral Therapy (ART) Failure in 6 Sub-Saharan African Countries: Implications for Second-Line ART Strategies," Clinical Infectious Diseases, Vol. 54, No. 11, 2012, pp. 16601669.

[31] S. Jallow, A. Alabi, R. Sarge-Njie, K. Peterson, H. Whittle, et al., "Virological Response to Highly Active Antiretroviral Therapy in Patients Infected with Human Immunodeficiency Virus Type 2 (HIV-2) and in Patients Dually Infected with HIV-1 and HIV-2 in the Gambia and Emergence of Drug Resistant Variants,” Journal of Clinical Microbiology, Vol. 47, No. 7, 2009, pp. 2200-2208. http://dx.doi.org/10.1128/JCM.01654-08

[32] E. A. Abar, A. Jlizi, Y. H. Darar, et al., "HIV-1 Drug Resistance Genotyping from Antiretroviral Therapy (ART) Naïve and First-Line Treatment Failures in Djiboutian Patients,” Diagnostic Pathology, Vol. 7, 2012, p. 138. http://dx.doi.org/10.1186/1746-1596-7-138

[33] V. Novitsky, C. W. Wester, V. DeGruttola, et al., "The Reverse Transcriptate 67N 70R 215Y Genptype Is the Predominant TAM; Athway Associated with Virologic Failure among HIV Type 1C-Infected Adults Treated with ZDV/ddl-Containing HAART in Southern Africa," AIDS Research and Human Retroviruses, Vol. 23, 2007, pp. 868-878. http://dx.doi.org/10.1089/aid.2006.0298

[34] J. Liu, J. Yue, S. Wu and Y. Yan, "Polymorphisms and Drug Resistance Analysis of HIV-1 CRF01_AE Strains Circuiting in Fujian Province, China," Archives of Virology, Vol. 152, No. 10, 2007, pp. 1799-1805. http://dx.doi.org/10.1007/s00705-007-1019-9

[35] UK Group on Transmitted HIV Drug Resistance, “Time Trends in Primary Resistance HIV Drugs in the United Kingdom: Multicenter Observational Study,” British Medical Journal, Vol. 331, No. 7529, 2005, pp. 1368-1373. http://dx.doi.org/10.1136/bmj.38665.534595.55

[36] N. A. Ingole, S. M. Kukreja and P.-R. Mehata, "Role of HIV-1 Viral Load in Initiating Antiviral Therapy," World Journal of AIDS, Vol. 1, No. 4, 2011, pp. 149-154. http://dx.doi.org/10.4236/wja.2011.14022

[37] WHO, "Clinical and Laboratory Monitoring of Antiretroviral therapy in Resource-Limited and Unlimited Settings,” HIV/AIDS Antiretroviral Newsletter, No. 4, 2000, 
pp. 1-4.

[38] S. P. Eholie, C. C. T. N’Dour, M. Cisse, E. Bissagnene and P. M. Girad, "Observance of Antiretroviral Treatments African Specificities,” Médecine et Maladies Infectieuses, Vol. 36, 2006, pp. 443-448.

[39] B. Shah, L. Walshe, D. G. Saple, et al., “Adherence to Antiretroviral Therapy and Virologic Suppression among HIV-Infected Persons Receiving Care in Private Clinics in Mumbai, India,” Clinical Infectious Diseases, Vol. 44, No. 9, 2007, pp. 1235-1244. http://dx.doi.org/10.1086/513429

[40] A. M. Geretti, C. Smith, A. Haberl, et al., "Determinants of Virological Failure after Successful Viral Load Suppression in First-Line Highly Active Antiretroviral Therapy,” Antiviral Therapy, Vol. 13, No 7, 2008, pp. 927936.

[41] M. A. Chesney, J. Ickovics, F. M. Hecht, et al., "Adherence: A Necessity of Successful HIV Combination Therapy,” AIDS, Vol. 13, Suppl. A, 1999, pp. S271-S278.

[42] A. J. Leigh Brown, S. D. Frost, W. C. Matthews, et al., "Transmission Fitness of Drug-Resistant Human Immunodeficiency Virus and the Prevalence of Resistance in the Antiretroviral-Treated Population," Journal of Infectious Diseases, Vol. 187, No. 4, 2003, pp. 683-686. http://dx.doi.org/10.1086/367989

[43] A. Fibrian, R. Wisaksana, A. Indrati, Y. Hartantri, et al., "Virology Failure and Drug Resistance during First Line Antiretroviral Treatment in Indolnesia," Journal of Medical Virology, Vol. 85, No. 8, 2013, pp. 1394-1401. http://dx.doi.org/10.1002/jmv.23606
[44] M. Vidya, S. Saravana, S. Uma, N. Kumarasamy, et al., "Genotypic HIV Type 1 Drug Resistance among Patients with Immunological Failure to First Line Antiretroviral Therapy on South India,” Antiviral Therapy, Vol. 14, No. 7, 2009, pp. 1005-1009. http://dx.doi.org/10.3851/IMP1411

[45] “Stanford HIV Drug Resistance Database,” 2013. http//hivdb.stanford.edu/pages/drugSummaries.html

[46] A. M. Geretti, "Clinical Implication of HIV Drug Resistance to Nucleoside Reverse Transcriptase Inhibitors," AIDS Reviews, Vol. 8, No. 4, 2006, pp. 210-220.

[47] V. A. Johnson, C. Vincent, H. F. Gunthard, P. Roger, P. Deenan, S. Robert, A. M. Wensing and D. D. Richman, "2011 Update of the Drug Resistance Mutation in HIV1,” Topics in Antiviral Medicine, Vol. 19, No. 4, 2011, pp. 156-164.

[48] E. P. Coakley, J. M. Gills and S. M. Hammer, "Phenotypic and Gonotypicrersistance Pattern of HIV-1 Isolate Derived from Individuals Treated with Diagnosing and Stavudine,” AIDS, Vol. 14, 2002, pp. F9-F15. http://dx.doi.org/10.1097/00002030-200001280-00002

[49] R. K. Gupta, A. Hill, A. W. Sawyer, et al., "Virological Monitoring and Resistant to First-Line Highly Active Antiretroviral Therapy in Adults Infected with HIV-1 Treated under WHO Guidelines: A Systematic Review and Mental Analysis,” Lancet Infectious Diseases, Vol. 9, 2009, pp. 409-417. http://dx.doi.org/10.1016/S1473-3099(09)70136-7 